\title{
Extracorporeal membrane oxygenation in pediatric cardiovascular care: Experience of a center in Argentina
}

\author{
María L. Pilán, M.D. ${ }^{a}$, Guillermo Moreno, M.D. ${ }^{a}$, Mariela Krynski, M.D. ${ }^{a}$, \\ Gisela Ponce, Nurse ${ }^{a}$, Mercedes Montonati, M.D. ${ }^{a}$, Mirian Lenz, M.D. ${ }^{a}$, \\ Ricardo Rodríguez, M.D. ${ }^{a}$, Javier Cornelis, M.D. ${ }^{b}$, Jorge Barreta, M.D. ${ }^{b}$, \\ Ricardo Magliola, M.D. ${ }^{a}$, Raquel Quiroz, B.S. ${ }^{a}$ and Pablo García Delucis, M.D. ${ }^{b}$
}

\begin{abstract}
Objective:Todescribetheresultsofextracorporeal membrane oxygenation in patients undergoing heart surgery and analyze the risk factors for morbidity and mortality.

Methods: Retrospective study conducted in cardiac patients under circulatory support. Outcome measures, diagnosis, surgery, Risk Adjustment for Congenital Heart Surgery (RACHS) score, implantation time, cannulation, length of support during stay, complications, survival, and follow-up were recorded. Risks were analyzed in relation to age, weight, RACHS score, single-ventricle or biventricular disease, implantation time, length of support and stay, and complications. Descriptive statistical and logistic regression analyses for risk factors were done.

Results: Among 5295hospitalizations, 72 patients required extracorporeal membrane oxygenation $(1.37 \%)$. Median age: 6.5 months (interquartile range [IQR]: 20 days-2 years); weight: $5.5 \mathrm{~kg}$ (IQR: 3.25-9.5); pump time: $188 \mathrm{~min}$ (IQR: $134-$ 246.5); clamp time: $92 \mathrm{~min}$ (65-117). Cannulation was done in the operating room in 34 cases $(47 \%)$. The median length of support was 3 days (IQR: $2-5$ ), and of stay, 20 days (IQR: 1132). Survival at discharge was $49 \% ; 8$ patients died during follow-up. The most common complication was bleeding $(57 \%)$. Weight $<5 \mathrm{~kg}$ $(p=0.01)$ and vasopressor use during support $(p=0.012)$ were associated with a risk for mortality. The survival rate at 10 years was $77 \%$; $84 \%$ of patients corresponded to functional class $1-2$, and $37 \%$ had some degree of developmental delay.

Conclusions: The most common complication was bleeding; weight and vasopressor use were associated with mortality.

Key words: congenital heart disease, extracorporeal membrane oxygenation, risk factors.
\end{abstract}

http: / / dx.doi.org/ 10.5546/ aap.2019.eng.157

mlpilan@gmail.com

Funding:

None.

Conflict of interest:

None.

Received: 5-8-2018.

Accepted: 1-8-2019

\section{INTRODUCTION}

Extracorporeal membrane oxygenation (ECMO) is an extracorporeal vital support technique that provides total or partial heart and/or lung support to patients with cardiac and/or refractory respiratory failure as a transition while making a decision and towards recovery, surgery or transplant. It is one of the most complex and powerful technological devices in medicine today and is part of the standard perioperative care in criticallyill children with congenital heart disease admitted to tertiary care facilities. There are different forms of mechanical circulatory support: some provide temporary heart and lung support, such as ECMO, while others only provide heart support, either to one or both ventricles (these are known as ventricular assist devices, VADs). ECMO is a short-term ( $<30$ days) mechanical circulatory support device that is most commonly used for perioperative care of children with congenital heart disease.$^{1-3}$ The most frequent indication is unsuccessful treatment in heart failure and postoperative heart surgery..$^{1-3}$ It has been estimated that $1-2 \%$ of surgery patients require ECMO. Due to its complexity, highly specific knowledge and training are needed to achieve adequate results. ${ }^{4}$

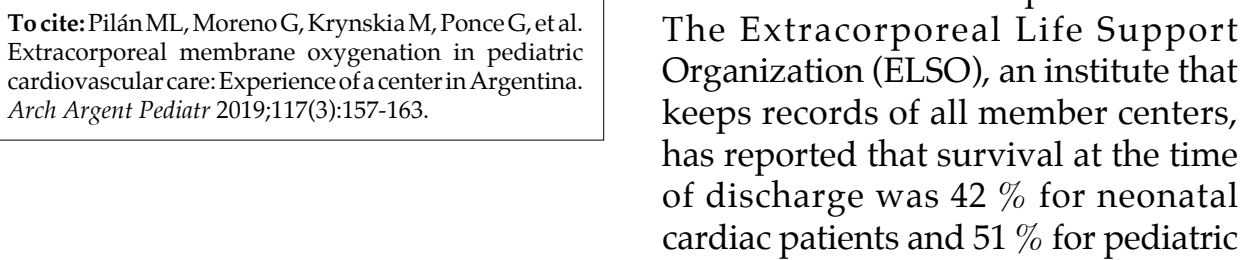

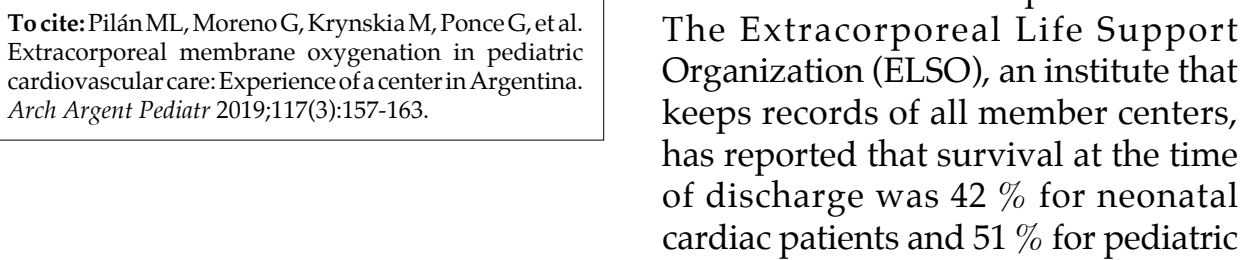

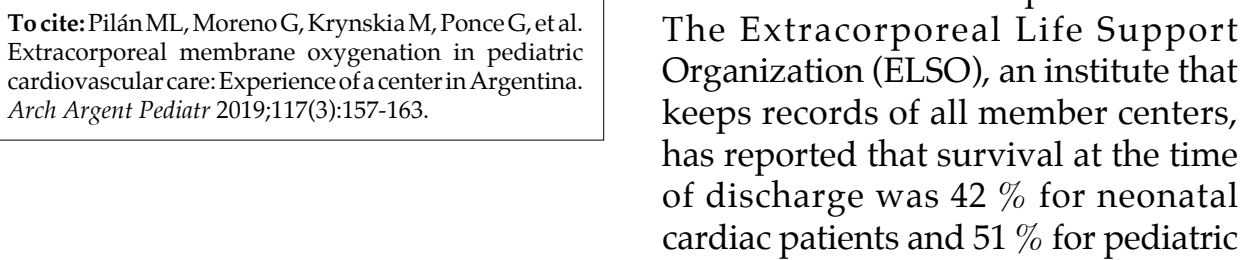

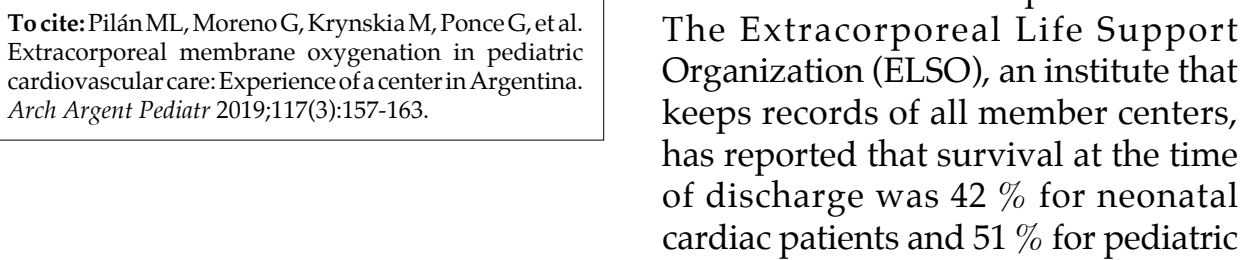

\begin{tabular}{l|l}
$\begin{array}{l}\text { Tocite:PilánML, MorenoG, KrynskiaM, Ponce G, etal. } \\
\text { Extracororeal membrane oxygenation in pediatric } \\
\text { cardiovascularcare: Experienceofacenterin Argentina. } \\
\text { Arch Argent Pediatr 2019;117(3):157-163. }\end{array}$ & $\begin{array}{l}\text { The Extracorporeal Life Su pport } \\
\text { Organization (ELSO), an institute that } \\
\text { keeps records of all member centers, } \\
\text { has reported that survival at the time } \\
\text { of discharge was } 42 \% \text { for neonatal } \\
\text { cardiac patients and } 51 \% \text { for pediatric }\end{array}$ \\
&
\end{tabular}

\begin{tabular}{l|l}
$\begin{array}{l}\text { Tocite: Pilán ML, MorenoG, Krynskia M, PonceG, etal. } \\
\text { Extracorporeal membrane oxygenation in pediatric } \\
\text { cardiovascular care: Experienceofacenterin Argentina. } \\
\text { Arch Argent Pediatr 2019;117(3):157-163. }\end{array}$ & $\begin{array}{l}\text { The Extracorporeal Life Support } \\
\text { Organization (ELSO), an institute that } \\
\text { keeps records of all member centers, } \\
\text { has reported that survival at the time } \\
\text { of discharge was } 42 \% \text { for neonatal } \\
\text { cardiac patients and } 51 \% \text { for pediatric }\end{array}$
\end{tabular} 
cardiac patients. ${ }^{5}$ In our hospital, 600 patients with congenital heart disease are operated on every year, and their mortality rate is close to $5 \%$. In 2006, we implemented an ECMO program for heart surgery. ${ }^{6-8}$ The objective of this study was to describe the results of ECMO support in patients undergoing heart surgery and analyze the risk factors for morbidity and mortality in our population.

\section{PATIENTS AND METHODS}

This was a retrospective data analysis of patients under ECMO at the Cardiovascular Care Unit of Hospital de Pediatría "Prof. Dr. Juan P. Garrahan," in the 2006-2016 period. Data were obtained from the department's database, which collected them prospectively for all surgery patients. The protocol was approved by the hospital's Institutional Review Board. These are dissociated data, so no informed consent was requested. The following data were included: demographic characteristics, cardiac diagnosis and surgery done, pump and clamp time, surgery complexity based on the Risk Adjustment for Congenital Heart Surgery (RACHS) method, ${ }^{9}$ ECMO initiation in the operating room or in the pediatric intensive care unit (PICU), central or peripheral cannulation, length of mechanical circulatory support in days, complications, survival upon decannulation, survival at the time of discharge, and long-term follow-up. Patients were divided into age groups: $<30$ days old, 1-12 months old, 1-18 years old, and adults. Due to the wide variability in terms of diagnosis, patients were divided into three groups for analysis: single-ventricle lesions, biventricular lesions, and myocardial disease (heart transplant and myocarditis).

Complications were categorized as per the ELSO's criteria into mechanical (air in circuit, thrombi in circuit, oxygenator failure, cannula problems or any problem requiring circuit change), hemorrhagic (gastrointestinal hemorrhage, cannulation site bleeding, surgical site bleeding, hemolysis), neurologic (seizures, brain hemorrhage, cerebral infarction, brain death), renal (renal failure, dialysis), respiratory (pneumothorax, pulmonary hemorrhage), cardiopulmonary (arrhythmia, cardiac arrest, vasopressor use during support, arterial hypertension requiring vasodilators, cardiac tamponade), and infectious (positive blood culture during support). During the 10-year clinical follow-up, neurologic status (motor and cognitive test, Clinical Adaptive Test/Clinical Linguistic and Auditory Milestone Scale [CAT/ CLAMS]) and functional capacity were assessed as per the American Society of Cardiology based on data from the medical records.

\section{Definitions}

ECMO survival: presence of native circulation $24 \mathrm{~h}$ after decannulation. Survival at the time of discharge: patient who was alive at the time of discharge or transfer to another hospital. ${ }^{5}$

The following were analyzed as risk factors for mortality: age and weight, RACHS complexity score, single-ventricle or biventricular repair, implantation time, days of support and stay, and complications.

Statistical analysis: Continuous outcome measures were reported as mean and standard deviation or as median and interquartile range (IQR). Categorical outcome measures were described as absolute values and percentage; their association was assessed using the $\chi^{2}$ test or Fisher's exact test.

To identify risk factors for survival/mortality at the time of discharge, a bivariate analysis was performed in order to assess the relation between this and other independent outcome measures. Then, a multivariate logistic regression model was developed, which included outcome measures with a $p$ value $<0.2$ in association with the Wald test. After this, outcome measures which showed a statistically significant association with the Wald test of $p<0.05$ were included. Effect sizes were reported as odds ratio (OR) with the corresponding $95 \%$ confidence interval (CI). The statistical software package used was Stata 10.1.

\section{RESULTS}

During the study period, 5295 patients were operated on under extracorporeal circulation (ECC); of them, 72 required ECMO (1.37\%). In all cases, venoarterial ECMO was used. Table 1 describes population data. Patients' median age was 6.5 months (IQR: 20 days-2 years), and their weight was $5.5 \mathrm{~kg}$ (IQR: $3.25-9.5$ ). Pump time was 188 min (IQR: 134-246.5); and clamp time was $92 \mathrm{~min}$ (IQR: 65-117). Table 2 shows patient data grouped by age. A singleventricle repair (hypoplastic left heart syndrome) was performed in $12 \%(\mathrm{n}=9)$. Besides, $72 \%$ $(\mathrm{n}=52)$ of patients required a RACHS-3 or -4 surgery. In 34 patients (47\%), the ECMO was implanted in the operating room; it was used as preoperative stabilization only in 4 patients 
(neonates with critical cyanosis) to allow for surgical repair in favorable conditions. Central cannulation was performed in $94.5 \%$ of patients. The most common indications were myocardial dysfunction $(69 \%)$ and dysfunction associated with pulmonary hypertension (PHT) $(11 \%)$, followed by cyanosis $(10 \%)$, cardiorespiratory arrest $(3 \%)$, respiratory causes $(3 \%)$, sepsis $(3 \%)$, and arrhythmia $(1 \%)$.

The median length of support was 3 days (IQR: $1-12$ days); $46 \%$ of patients required hemofiltration or hemodiafiltration. Vasoactive drugs were needed during support in $12 \%$. Complications were observed in $72 \%$ of patients; bleeding was the most common one $(56.9 \%)$. The median length of stay was 20 days (IQR: 1 -34 days). Survival at the time of discharge was $49 \%(\mathrm{n}=35)$ (Table 2$)$.

Table 3 shows the detailed results of the bivariate analysis of risk factors for survival/ mortality. The multivariate model showed that all patients who required vasopressors under ECMO died $(p=0.012)$. Since this outcome measure was an accurate predictor of mortality, it was not included in the multivariate model; therefore, the OR and $95 \%$ CI could not be estimated. In the multiple model, weight $<5 \mathrm{~kg}$ was an associated factor that acted as predictor of risk for survival/ mortality at the time of discharge, regardless of

TABle 1. Description of the population. N: 72

\begin{tabular}{lcc}
\hline Outcome measure & Median & IQR \\
\hline Age (months old) & 6.5 & $(0.6-48)$ \\
Weight $(\mathrm{kg})$ & 5.5 & $(3.25-9.5)$ \\
ECC time (min) & 188 & $(134-246.5)$ \\
Clamp time (min) & 92 & $(65-117)$ \\
Length of support (days) & 3 & $(2-5)$ \\
Length of MV (days) & 11 & $(6-20)$ \\
Length of stay (days) & 20 & $(11-32)$ \\
\hline
\end{tabular}

IQR: interquartile range; ECC: extracorporeal circulation; $\mathrm{MV}$ : mechanical ventilation. other assessed outcome measures $(p=0.01)$, OR: 0.28 (95 \% CI: 0.10-0.74).

During the 10-year follow-up period, it was confirmed that 19 patients were alive at the time of this study, whereas 8 had died. Of them, $84 \%$ $(\mathrm{n}=16)$ corresponded to functional class 1-2. In 10 patients $(53 \%)$, neurodevelopment was adequate for their age, while in 7 (37 \%), varying degrees of developmental delay were observed; no data could be collected in 2 (10 \%) (Figure 1).

\section{DISCUSSION}

In recent years, heart surgeries for congenital heart disease have become increasingly complex, and therefore it is necessary to offer techniques like ECMO, which provide time for myocardial function recovery. ${ }^{1,10}$ According to the ELSO, in January 2016, the survival rate with cardiac ECMO was $51 \%$ in pediatric patients. ${ }^{5}$ Several articles have mentioned the importance of the association between the site's volume and the improvement of survival among patients who require this treatment for heart indications; hence, it is very important that services be regionalized and centralized to provide such specific techniques. ${ }^{4,11}$ In our hospital, one of the main referral centers, $1.37 \%$ of surgery patients required $\mathrm{ECMO}$, and their survival at the time of discharge was $49 \%$. The most common indication was myocardial dysfunction during surgery (difficulty to remove ECC) or within $24 \mathrm{~h}$ after cardiotomy in the PICU.

Several studies have observed a higher mortality in patients who required ECMO in the operating room compared to the intensive care unit (ICU), whereas other have reported an increased mortality in patients who started ECMO early in the ICU after heart surgery. ${ }^{2,3,11,12}$ Recently, in a retrospective study based on the analysis of multiple databases, no association was established between ECMO initiation time and mortality. ${ }^{13}$

TABLE 2. Description of the population by age group

\begin{tabular}{lcccc}
\hline & $<\mathbf{3 0} \mathbf{~ d}$ & $\mathbf{1 ~ m . -} \leq \mathbf{1 2} \mathbf{~ m .}$ & $>\mathbf{1 2} \mathbf{~ m . - 1 8} \mathbf{~ a . ~}$ & $>\mathbf{1 8}$ a. \\
\hline No. & 18 & 28 & 24 & 2 \\
Age (median and IQR) & $11 \mathrm{~d} .(6-18)$ & $4 \mathrm{~m} .(2.5-7.35)$ & 3 a. $(1.5-4)$ & 22.8 a. $(18-27)$ \\
Weight $(\mathrm{kg})$ & $3(2.82-3.3)$ & $4.95(3.85-6)$ & $10(8.25-13)$ & $67.5(60-75)$ \\
Single-ventricle & $4(22 \%)$ & $5(18 \%)$ & - & - \\
RACHS $\geq 3$ & $100 \%$ & $64 \%$ & $75 \%$ & $0 \%$ \\
Length of support (days) & $3(3-4)$ & $3.5(2-6)$ & $3(2.5-4.5)$ & $4.5(1-8)$ \\
Length of stay (days) & $20.5(12-30)$ & $15(6-32)$ & $26.5(12-34)$ & $25.5(13-38)$ \\
Survival at the time of discharge & $7(39 \%)$ & $12(43 \%)$ & $14(58 \%)$ & $2(100 \%)$ \\
\hline
\end{tabular}

IQR: interquartile range; d.: days old; m.: months old; y.: years old; RACHS: Risk Adjustment for Congenital Heart Surgery. 
In our series, no significant differences were observed between both groups. One of the most important aspects in the indication of this procedure is the selection of the adequate time for support. Identifying such moment is critical because a late intervention would worsen outcomes. Different scores have been developed in this regard; however, most are targeted at adult patients and not easily adapted to our population. ${ }^{14}$ Most groups agree that the optimal

TABLE 3. Bivariate analysis of risk factors for survival at the time of discharge*

\begin{tabular}{|c|c|c|c|c|c|}
\hline \multicolumn{2}{|l|}{ Outcome measure } & \multirow{2}{*}{$\begin{array}{c}\text { \% survival } \\
47.6 \\
55.6\end{array}$} & \multirow{2}{*}{$\frac{\text { OR }}{0.73}$} & \multirow{2}{*}{$\frac{95 \% \text { CI }}{0.18-2.96}$} & \multirow{2}{*}{$\frac{P}{0.65}$} \\
\hline Repair & $\begin{array}{l}\text { Single-ventricle } \\
\text { Biventricular }\end{array}$ & & & & \\
\hline Cannulation & $\begin{array}{l}\text { Central } \\
\text { Peripheral }\end{array}$ & $\begin{array}{c}46 \\
66.7\end{array}$ & 0.43 & $0.098-1.86$ & 0.24 \\
\hline RACHS-1 & $\begin{array}{l}\leq 2 \\
\geq 3\end{array}$ & $\begin{array}{l}63.5 \\
43.5\end{array}$ & 0.44 & $0.11-1.69$ & 0.22 \\
\hline Bleeding & $\begin{array}{l}\text { Yes } \\
\text { No }\end{array}$ & $\begin{array}{l}45.2 \\
55.2\end{array}$ & 0.67 & $0.26-1.73$ & 0.41 \\
\hline Vasopressor use & $\begin{array}{l}\text { Yes } \\
\text { No }\end{array}$ & $\begin{array}{c}0 \\
55.2\end{array}$ & -- & -- & 0.012 \\
\hline $\begin{array}{l}\text { Mechanical } \\
\text { complications }\end{array}$ & $\begin{array}{l}\text { Yes } \\
\text { No }\end{array}$ & $\begin{array}{l}28.6 \\
54.4\end{array}$ & 0.33 & $0.09-1.19$ & 0.08 \\
\hline $\begin{array}{l}\text { Renal } \\
\text { complications }\end{array}$ & $\begin{array}{l}\text { Yes } \\
\text { No }\end{array}$ & $\begin{array}{l}50 \\
50\end{array}$ & 1 & $0.13-7.53$ & 0.95 \\
\hline Weight $<5 \mathrm{~kg}$ & $\begin{array}{l}\text { Yes } \\
\text { No }\end{array}$ & $\begin{array}{l}32.3 \\
63.1\end{array}$ & 0.28 & $0.10-0.74$ & 0.009 \\
\hline Age & $\begin{array}{l}<1 \text { month } \\
\geq 1 \text { month }\end{array}$ & $\begin{array}{l}38.9 \\
51.8\end{array}$ & 0.52 & $0.18-1.53$ & 0.34 \\
\hline
\end{tabular}

${ }^{*} \chi^{2}$ test.

IQR: interquartile range; OR: odds ratio; CI: confidence interval; RACHS: Risk Adjustment for Congenital Heart Surgery.

FIGURE 1. Clinical follow-up at 10 years

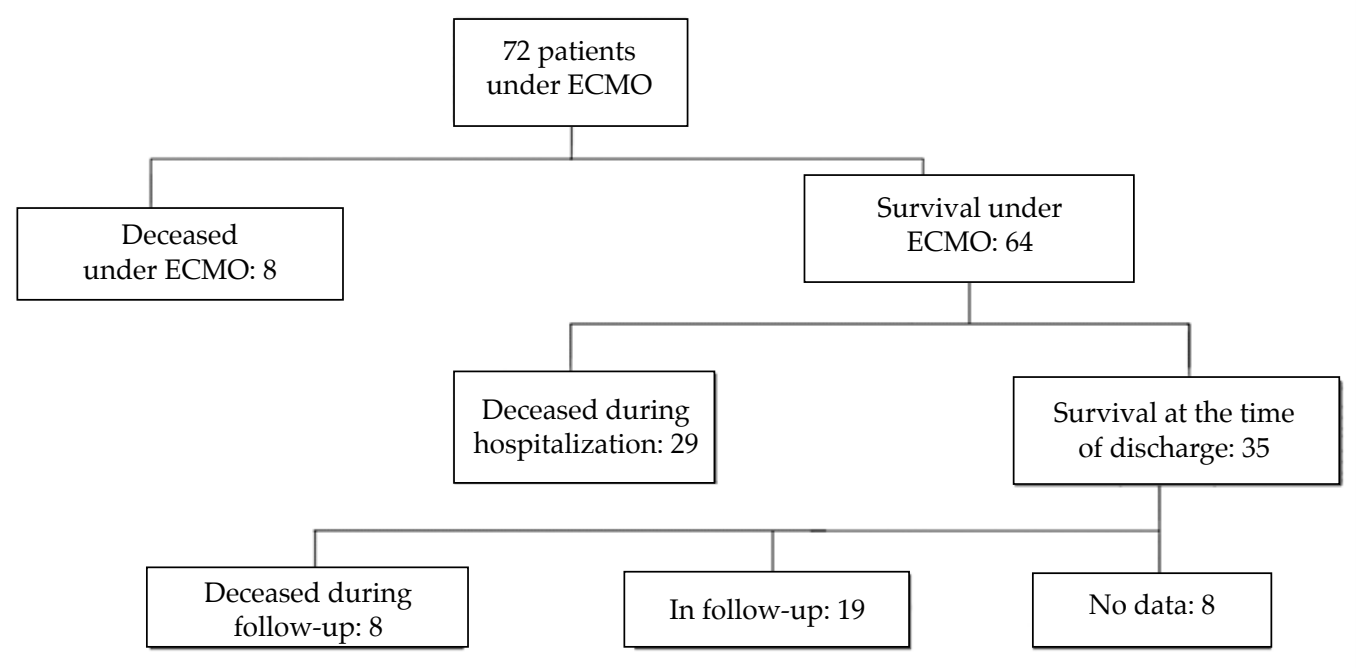

ECMO: extracorporeal membrane oxygenation. 
moment for ECMO initiation should be based on the clinical setting. ${ }^{13}$

An analysis by the ELSO of the factors associated with mortality in neonates requiring ECMO due to heart conditions mentions acidosis (arterial blood $\mathrm{pH}<7.20$ ), lactic acid $>5 \mathrm{mmol}$ (as tissue perfusion markers), and the need for mechanical ventilation (MV) prior to ECMO initiation as the factors associated with an increase in mortality. ${ }^{12,13}$ These studies suggest that a timely indication of ECMO initiation is one of the most important prognostic factors, especially in the neonatal population. ${ }^{15}$

In our experience, the need for ECMO support is considered for patients in whom the bypass pump cannot be removed or who have a severely low postcardiotomy cardiac output, those who are refractory to standard treatment, based on objective parameters such as tissue hypoperfusion (metabolic acidosis [ph $<7.25]$ and lactic acidosis [lactate $>4 \mathrm{mmol}$ and increasing]), venous oxygen saturation $<40 \%$, oligoanuria, and increasing inotrope doses (adrenaline $>0.15$, noradrenaline $>0.15$ and increasing, and vasopressin $>0.002$ ).

Another risk factor for mortality recognized in most series is single-ventricle physiology.${ }^{15-17}$ In our series, most patients had biventricular repairs; no significant differences were observed in terms of mortality between both groups.

In numerous series, weight $<4 \mathrm{~kg}$, prematurity, length of support $>8$ days, and inotrope and / or dialysis requirement under ECMO were other outcome measures associated with mortality. ${ }^{13,17}$

In our series, only weight $<5 \mathrm{~kg}$ and intravenous vasopressor need were significantly associated with mortality. The most common complication in our patients was bleeding $(56.9 \%)$.

Werho et al., conducted a retrospective analysis of ELSO data in pediatric cardiac patients under ECMO and concluded that bleeding was a complication in more than half of them, that mediastinal exploration prior to $\mathrm{ECMO}$, a more complex surgery, cannulation during the early post-operative period, and a longer length of ECC were the factors associated with a hemorrhagic complication in these patients and a risk factor associated with morbidity and mortality..$^{18}$

The implementation of an anticoagulation protocol by hematologists, including hemostatic supplementary tests, in our facility, has helped to reduce this complication, especially in the population of neonates, who are at a higher risk. ${ }^{19,20}$ In our series, $46 \%$ of patients required hemofiltration and/or hemodiafiltration, but it was not associated with a greater mortality. In most cases, such dialysis measures were indicated due to excess fluids during the perioperative period and the need to achieve a negative balance and not to the presence of acute renal failure. ${ }^{21,22}$

ECMO is also associated with morbidity. The causes of this are multifactorial. The severity of heart disease, non-cardiac anomalies, organ hypoperfusion during the critical phase of disease, and ECMO procedure itself may contribute to morbidity. ${ }^{2,10.23,24}$ Thus, in recent years, in addition to survival at the time of discharge, other outcomes have been assessed, such as neurodevelopment, quality of life, and late mortality ${ }^{25-27}$ During the long-term follow-up, primary care facilities have concluded that most of these patients present a significant morbidity, a worse neurodevelopment, and a poorer quality of life than the normal population. ${ }^{28-30}$

In our series, 8 patients died during follow-up and only 19 completed subsequent clinical visits. Of them, $84 \%$ (n: 16) corresponded to functional class 1-2, and $37 \%$ (n: 7) had varying degrees of developmental delay. The introduction of these patients to the hospital's follow-up program of patients with complex chronic conditions will provide a better future knowledge of our population's neurodevelopment and quality of life. $^{31}$

\section{CONCLUSIONS}

The survival rate at the time of discharge in the ECMO program for heart surgery of Hospital de Pediatría "Prof. Dr. Juan P. Garrahan" was $49 \%$. The factors associated with a higher risk for mortality were weight $<5 \mathrm{~kg}$ and vasopressor requirement during support. The most common complication was bleeding; however, it was not associated with a higher mortality. During the 10-year follow-up, the survival rate was $77 \%$, and $84 \%$ of patients remained in functional class 1-2, while $37 \%$ showed varying degrees of developmental delay.

\section{Acknowledgments}

We would like to thank José Suárez, M.D., for his contribution to this program. And Maria Althabe, M.D., for making a critical reading.

\section{REFERENCES}

1. Thiagarajan RR. Extracorporeal Membrane Oxygenation for Cardiac Indications in Children. Pediatr Critic Care Med. 2016; 17(8 Suppl 1):S155-9. 
2. Cashen K, Hollis TK, Delius RE, Meert KL. Extracorporeal Membrane Oxygenation for Pediatric Cardiac Failure: Review with a Focus on Unique Subgroups. Prog Pediatr Cardiol. 2016; 43:105-11.

3. Mesher AL, McMullan DM. Extracorporeal Life Support for the Neonatal Cardiac Patients: Outcomes and New Directions. Semin Perinatol. 2014; 38(2):97-103.

4. Freeman CL, Bennett TD, Casper C, Larsen GY, et al. Pediatric and neonatal extracorporeal membrane oxygenation: does center volume impact mortality? Crit care Med. 2014; 42(3):512-9.

5. Extracorporeal Life Support Organization. ECLS Registry Report: International Summary. January 2016. [Accessed on: January $\left.8^{\text {th }}, 2019\right]$. Available at:https: / / www.elso.org/ Registry/Statistics/InternationalSummary.aspx.

6. Althabe M, Rodríguez R, Balestrini M, Charroqui A, et al. Morbilidad en cirugía de cardiopatía congénita en un hospital público en Argentina. Arch Argent Pediatr. 2018; 116(1):e14-8.

7. Moreno GE, Magliola RH, Pilan ML, Althabe M, et al. Asistencia circulatoria mecánica en pediatría. Experiencia en el Hospital de Pediatría Dr. Juan P. Garrahan. Argentina. Arch Cardiol Mex. 2014; 84(4):256-61.

8. Magliola R, Althabe M, Moreno G, Lenz A, et al. Cirugía cardíaca reparadora en recién nacidos. Experiencia de 5 años en cirugia neonatal con circulación extracorpórea. Arch Argent Pediatr. 2009; 107(5):417-22.

9. Jenkins K, Gauvreau K, Newburger J, Spray TL, et al. Consensus-based method for risk adjustment for surgery for congenital heart disease. J Thorac Cardiovasc Surg. 2002; 123(1):110-8.

10. Paden ML, Rycus PT, Thiagarajan RR, ELSO Registry. Update and Outcomes in Extracorporeal Life Support. Semin Perinatol. 214; 38(2):65-70.

11. Allan CK, Thiagarajan RR, Del Nido PJ, Roth SJ, et al. Indication for initiation of mechanical circulatory supports impacts survival of infants with shunted single-ventricle circulation supported with extracorporeal membrane oxygenation. J Thorac Cardiovasc Surg. 2007; 133(3):660-7.

12. Chrysostomou C, Morell VO, Kuch BA, O'Malley E, et al. Short-and intermediate-term survival after extracorporeal membrane oxygenation in children with cardiac disease. J Thorac Cardiovasc Surg. 2013; 146(2):317-25.

13. Gupta P, Robertson MJ, Rettiganti M, Seib PM, et al. Impact of timing of ECMO initiation on outcomes after pediatric heart surgery: a multi-institutional analysis. Pediatr Cardiol. 2016; 37(5):971-8.

14. Schmidt M, Burrel A, Roberts L, Bailey M, et al. Predicting survival after ECMO for refractory cardiogenic shock: the survival after veno-arterial-ECMO (SAVE)-score. Eur Heart J. 2015; 36(33):2246-56.

15. Kumer TK, Zuracowski D, Dalton H, Talwar S, et al. Extracorporeal membrane oxygenation in postcardiotomy patients: factors influencing outcomes. J Thorac Cardiovasc Surg. 2010; 140(2):330-6.

16. Mascio CE, Austin E 3rd, Jacobs JP, Jacobs ML, el at. Perioperative mechanical circulatory support in children: an analysis of the Society of Thoracic Surgeons Congenital Heart Surgery Database. J Thorac Cardiovasc Surg. 2014; 147(2):658-64.
17. Ford MA, Gauvreau K, McMullan M, Almodovar MC, et al. Factors associated with mortality in neonates requiring extracorporeal membrane oxygenation for cardiac indications: analysis of the extracorporeal life support organization registry data. Pediatr Crit Care Med. 2016; 17(9):860-70.

18. WerhoDK, PasqualiSK, YuS, DonohueJ, etal.Hemorrhagic complicationsin pediatric cardiac patients on extracorporeal membrane oxygenation: an analysis of the Extracorporeal Life Support Organization Registry. Pediatr Crit Care Med. 2015; 16(3):276-88.

19. Saini A, Spinella PC. Management of anticoagulation and hemostasis for pediatric extracorporeal membrane oxygenation. Clin Lab Med. 2014; 34(3):655-73.

20. Baird CW, Zurakowski D, Robinson B, Gandhi S, et al. Anticoagulation and extracorporeal membrane oxygenation: impact of activated clotting time a heparin dose on survival. Ann Thorac Surg. 2007; 83(3):912-9.

21. Askenazi DJ, Ambalavanan N, Hamilton K, Cutter G, et al. Acute kidney injury a renal replacement therapy independently predict mortality in neonatal and pediatric noncardiac patients on extracorporeal membrane oxygenation. Pediatr Crit Care Med. 2011; 12(1):e1-6.

22. Han SS, Kim, HJ, Lee SJ, Kim WJ, et al. Effects of renal replacement therapy in patients receiving extracorporeal membrane oxygenation: a meta-analysis. Ann Thorac Surg. 2015; 100(4):1485-95.

23. Chandler HK, Teppa B, Johnson KA, McCracken C, et al. Determining comorbidities and quality of life among pediatric survivors of extracorporeal life support. J Crit Care. 2015; 30(5):1085-9.

24. García Guerra G, Robertson CM, Alton GY, Joffe AR, et al. Quality of life 4 years after complex heart surgery in infancy. J Thorac Cardiovasc Surg. 2013; 145(2):482-8.e2.

25. Wagner K, Risnes I, Bermtsen T, Skarbø AB, et al. Clinical and psychosocial follow-up study of children treated with extracorporeal membrane oxygenation. Ann Thorac Surg. 2007; 84(4):1349-55.

26. Massaro AN, El-Dib M, Glass P, Aly H. Factors associated with adverseneurodevelopmental outcomes in infants with congenital heart disease. Brain Dev. 2008; 30(7):437-46.

27. Elias MD, Achuff BJ, Ittenbach RF, Ravishankar C, et al. Long-term outcomes of pediatric cardiac patients supported by extracorporeal membrane oxygenation. Pediatr Critc Care Med. 2017; 18(8):787-94

28. García Guerra G, Robertson CMT, Alton GY, Joffe AR, et al. Heath-related quality of life in pediatric cardiac extracorporeal life support survivors. Pediatr Crit Care Med. 2014; 15(8):720-7.

29. Ibrahim AE, Duncan BW, Blume ED, Jonas RA. Long-term follow-up of pediatric cardiac patients requiring mechanical circulatory support. Ann Thorac Surg. 2000; 69(1):186-92.

30. Costello JM, O'Brien M, Wypij D, Shubert J, et al. Quality of life of pediatric cardiac patients who previously required extracorporeal membrane oxygenation. Pediatr Crit Care Med. 2012; 13(4):428-34.

31. Marin DN, Sorbara L. conducta adaptativa y calidad de vida en niños de 3 a 6 años con cardiopatías congénitas. Su relación con el medio ambiente de crianza. Med Infant. 2017; 24(2):78-86. 